\title{
Erratum to: Social Exclusion in Later Life: a Systematic Review of the Literature
}

\author{
Sofie Van Regenmortel ${ }^{1}$ - Liesbeth De Donder ${ }^{1}$ - Sarah Dury ${ }^{1}$. \\ An-Sofie Smetcoren ${ }^{1} \cdot$ Nico De Witte $^{1,2} \cdot$ Dominique Verté $^{1}$
}

Published online: 16 August 2017

(C) Springer Science+Business Media B.V. 2017

\section{Erratum to: Population Ageing \\ DOI: $10.1007 / \mathrm{s} 12062-016-9145-3$}

The original version of this article unfortunately contained missing data in Table 2 . The complete Table 2 is shown below.

The online version of the original article can be found at http://dx.doi.org/10.1007/s12062-016-9145-3

\section{Sofie Van Regenmortel}

sofie.van.regenmortel@vub.ac.be

Liesbeth De Donder

liesbeth.de.donder@vub.ac.be

Sarah Dury

sarah.dury@vub.ac.be

An-Sofie Smetcoren

an-sofie.smetcoren@vub.ac.be

Nico De Witte

nico.de.witte@vub.ac.be

Dominique Verté

dominique.verte@vub.ac.be

1 Faculty of Psychology and Educational Sciences, Vrije Universiteit Brussel, Pleinlaan 2, 1050 Brussels, Belgium

2 Faculty of Education, Health and Social Work, University College Ghent, Ghent, Belgium 


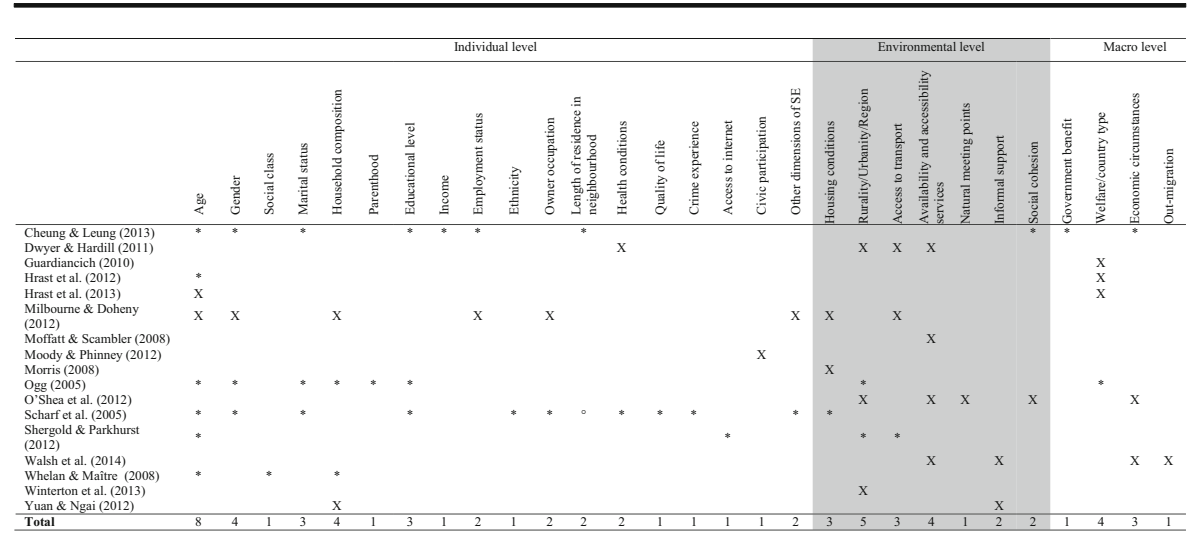

Note: X The study qualitatively or descriptively examined this determinant

*The study found a significant association of this risk factor with social exclusion or one of its dimensions

${ }^{\circ}$ The study found no significant association of this risk factor with social exclusion or one of its dimensions 